\title{
Actividad inhibitoria de plantas in vitro de Drosera capillaris sobre Mycobacterium tuberculosis
}

\author{
Inhibitory activity of in vitro plants from Drosera capillaris against \\ Mycobacterium tuberculosis
}

\author{
Jimmy Alvarado', Hilda Vásquez¹, Guillermo E. Delgado', Dalva Trevisan², Oscar \\ Horna $^{3}$, Jurandir Pereira ${ }^{2}$ y Consuelo Rojas ${ }^{1 *}$
}

\begin{abstract}
1Facultad de Ciencias Biológicas, Universidad Nacional Pedro Ruiz Gallo, Ciudad Universitaria, Juan XXIII No 391, Lambayeque - Perú. *E-mail: crojasi2002@yahoo.es 2Departamento de Química Centro de Ciências Exatas. Universidade Estadual de Londrina, Paraná, Brasil.

3Dirección Regional de Salud. Laboratorio de Referencia Regional en Salud Pública -Lambayeque, Perú. Av. Salaverry No 1610 Chiclayo.

${ }^{*}$ Autor para correspondencia
\end{abstract}

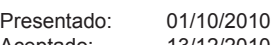

\begin{abstract}
Resumen
El objetivo del trabajo fue demostrar la actividad inhibitoria de plantas in vitro de Drosera capillaris (Droseraceae) sobre Mycobacterium tuberculosis. Las plantas de $D$. capillaris fueron propagadas en cultivos in vitro a partir de plántulas y hojas adultas. Se utilizó metanol como solvente de extracción y el sistema de cromatografía a gas en la determinación de los metabolitos secundarios. El medio de cultivo Lowenstein-Jensen, suplementado con las concentraciones 1,$25 ; 2,5$ y $5 \mathrm{mg} / \mathrm{mL}$ de la fracción clorofórmica del extracto crudo metanólico, fue utilizado en la evaluación del crecimiento de cinco cepas de $M$. tuberculosis. Los resultados indicaron que plantas de $3-5 \mathrm{~cm}$ de altura fueron obtenidas después de $10-12$ meses de cultivo in vitro. La naftoquinona plumbagina fue determinada por comparación con el tiempo de retención del patrón correspondiente, así como de otros compuestos hidrocarbonados similares de cadena larga. El crecimiento de $M$. tuberculosis fue inhibido en un rango de $40-93,1 \%$ en los tratamientos 2,5 y $5 \mathrm{mg} / \mathrm{mL}$. La concentración inhibitora mínima $(\mathrm{CIM})$ y $\mathrm{CIM}_{90}$ fue $1,25 \mathrm{mg} / \mathrm{mL}$ y $2,5-5 \mathrm{mg} / \mathrm{mL}$, respectivamente. Se demostró la acción antibacteriana del extracto metanólico de plantas in vitro de $D$. capillaris, probablemente por acción de la plumbagina y de los otros metabolitos se-
\end{abstract} cundarios detectados.

Palabras claves: cultivo de tejidos, extracto metanólico, fitoterapia, plumbagina, tuberculosis.

\section{Abstract}

The objective of the work was to demonstrate the inhibitory activity of in vitro plants of Drosera capillaris (Droseraceae) on Mycobacterium tuberculosis. The plants of $D$. capillaris were propagated in in vitro cultures from plantlets and mature leaves. It was used metanolic extract and gas chromatography to determinate secondary metabolites. Lowenstein-Jensen media, supplemented with 1.25; 2.5 y $5 \mathrm{mg} / \mathrm{mL}$ concentrations of cloroformic fraction obtain from metanolic crude extract, was used in the growth evaluation of five $M$. tuberculosis strains. The results indicated that plantlets of $3-5 \mathrm{~cm}$ up to, were obtained $10-12$ months after in vitro culture. The naphtoquinone plumbagin was determinated by comparison with currently pattern retention, like as another hidrocarbonic compounds seem to long chain. M. tuberculosis growth was inhibited in $40-93.1 \%$ range, 2.5 and $5 \mathrm{mg} / \mathrm{mL}$ treatments, respectively. The minimum inhibitory concentration (MIC) y $\mathrm{MIC}_{90}$ was $1.25 \mathrm{mg} / \mathrm{mL}$ and $2.5-5 \mathrm{mg} / \mathrm{mL}$, respectively. Was showed the antibacterial activity in metanolic extract of $D$. capillaris in vitro plants, probably by the action of the plumbagin and another secondary compounds found.

Keywords: Metanolic extract, phytotherapy, plumbagin, tissue cultura, tuberculosis.

\section{Introducción}

La tuberculosis (TBC) es una enfermedad infecto-contagiosa causada por Mycobacterium tuberculosis, también conocido como bacilo de Koch. Es considerada la enfermedad más prevalente en el mundo y solo en el 2006 se estimó en 9,2 millones (139 por 100000 habitantes) los nuevos casos de infectados con TBC, de los cuales 500000 fueron multidrogo resistentes (resistentes a isoniacida y rifampicina); el número de muertes fue de 1,7 millones o 200 fallecidos por hora (WHO, 2006). Alrededor del $95 \%$ de los casos y $98 \%$ de muertes por TBC ocurren en los países en vías de desarrollo, en tanto que el 75\% de los casos que se presentan en estos países están en el grupo de edad económicamente activa (de 15 a 50 años); en el Perú la tasa de morbilidad en el año 2007 alcanzó la cifra de 125,1 por 100 000 habitantes (Bonilla 2008).

Precisamente, la resistencia a drogas antituberculosas y la co-infección TB-VIH constituyen una seria amenaza para los programas nacionales de control de TB en el mundo y en especial en los países en desarrollo (Aziz et al. 2006, Asencios et al. 2009), de allí la necesidad de formular nuevas y variadas estrategias en el control de la enfermedad donde no solamente se considere el aspecto biomédico sino también el aspecto social (Jave 2009, Ticona 2009).
La familia Droseraceae, conocidas como plantas carnívoras, comprende 4 géneros entre los que se encuentra Drosera con 125 especies distribuidas en todo el mundo incluyendo regiones tropicales y tundras, excepto en desiertos y la Antártida (Culham \& Gornall 1994). Drosera capillaris Poir. ("atrapainsectos") se distribuye desde América del Norte hasta Venezuela y Brasil (Silva \& Giulietti 1997) pero no ha sido reportada para la flora del Perú (Brako \& Zarucchi 1993).

Drosera capillaris, al igual que otras especies "carnívoras", presenta diversas adaptaciones morfológicas y anatómicas para nutrirse de insectos que caen en sus trampas; éstas se encuentran provistas de glándulas pedunculadas con exudados pegajosos que atraen y digieren a los insectos gracias a sus enzimas proteolíticas, lo que constituye una respuesta evolutiva a su crecimiento en hábitats deficientes en nitrógeno (Cronquist 1988).

En cultivo de tejidos, desde los primeros trabajos realizados en D. rotundifolia (Simola 1978), diversos protocolos en micropropagación, organogénesis directa e indirecta y embriogénesis somática, han sido desarrollados hasta en 12 especies de Drosera (Šamaj et al. 1999); sin embargo, en D. capillaris no ha sido realizado trabajo alguno en cultivo de tejidos. Por otro lado, numerosas especies de Drosera son usadas tradicionalmente para varios propósitos medicinales, como agentes antitusígenos 
y antiespasmódicos y antiasmáticos; en infecciones bronquiales y afecciones pulmonares (Šamaj et al. 1999). Todo ello debido a la presencia de las naftoquinonas, metabolitos secundarios normalmente sintetizados y acumulados en varias especies de Drosera (Culham \& Gornall 1994, Zenk et al. 1969). Entre las naftoquinonas más importantes tenemos la plumbagina y la 7-metiljuglona (Finnie \& van Staden 1993), las que fueron estudiadas en diferentes especies de Drosera como marcadores quimiotaxonómicos (Culham \& Gornall 1994, Zenk et al. 1969). Estas naftoquinonas, además, tienen propiedades antivirales, antibacterianas, antifúngicas, anticancerígenas, antileprósicas y antiescleróticas (Šamaj et al. 1999).

Por estas razones en el presente trabajo se ha estudiado la actividad inhibitoria del extracto crudo metanólico de plantas micropropagadas in vitro de D. capillaris sobre Mycobacterium tuberculosis causante de la tuberculosis.

\section{Material y métodos}

Material biológico.- El material vegetal fue colectado en setiembre de 1988 en el Valle del Cauca, Cali (Colombia) e introducido en condición in vitro en la Unidad de Recursos Genéticos del Centro Internacional de Agricultura Tropical (CIAT), Cali. En tal condición fue transferido por el Dr. Guillermo E. Delgado Paredes al Laboratorio de Cultivo de Tejidos y Recursos Genéticos de la Universidad Nacional Pedro Ruiz Gallo (UNPRG), Lambayeque (Perú), donde se conserva por subcultivos anuales. La especie fue identificada como Drosera capillaris Poir. consultando el trabajo sobre Droseraceae del Brasil (Silva \& Giulietti 1997) y verificado por la especialista en Droseraceae, Dra. Tania R.S. Silva, del Instituto de Biociências de la Universidad de São Paulo (Brasil). Muestras herborizadas han sido depositadas en el Herbario Pedro Ruiz Gallo de la Facultad de Ciencias Biológicas de la UNPRG.

El material microbiológico estuvo constituido por cinco cepas de Mycobacterium tuberculosis, aisladas, identificadas y codificadas (C1, C2, C3, C4 y C5) en el Área de TBC del Laboratorio de Micobacterias (Laboratorio de Referencia Regional en Salud Pública, Lambayeque, Perú).

Micropropagación.- Plantas adultas in vitro de D. capillaris, de 10 - 12 meses de edad, fueron utilizadas en el proceso de micropropagación. Los explantes estuvieron constituidos por pequeñas plántulas con 5-10 hojas y hojas adultas individuales de 15 mm de longitud; y fueron cultivados, en condiciones asépticas, en frascos de vidrio transparentes conteniendo el medio de cultivo conformado por las sales minerales MS (Murashige \& Skoog, 1962), las vitaminas tiamina. $\mathrm{HCl} 1 \mathrm{mg} / \mathrm{L}$ y m-inositol $100 \mathrm{mg} / \mathrm{L}$, los reguladores de crecimiento ácido naftalenacético (ANA) y ácido giberélico $\left(\mathrm{AG}_{3}\right) 0,02 \mathrm{mg} / \mathrm{L}$, respectivamente, y sacarosa $2 \%$. El pH del medio de cultivo fue ajustado en 5,8 $\pm 0,1$ con $\mathrm{NaOH}$ y $\mathrm{HCl} 0,5 \mathrm{~N}$, respectivamente, antes de la gelificación con phytagel 0,3\%. La esterilización se realizó en autoclave a 120 ${ }^{\circ} \mathrm{C}$ de temperatura y $15 \mathrm{lbs} / \mathrm{pulg}^{2}$ de presión durante 20 minutos.

Obtención del extracto.- Plantas in vitro de 10-12 meses de edad fueron deshidratadas a temperatura ambiente bajo sombra durante $24 \mathrm{~h}$ y luego secadas a estufa a $40{ }^{\circ} \mathrm{C}$ por $48 \mathrm{~h}$; posteriormente, fueron molidas en mortero de porcelana hasta constituir un polvo fino; $54 \mathrm{~g}$ de esta masa fue sometida a extracción con metanol $(\mathrm{MeOH})$ por dos veces consecutivas con permanencia del solvente por $48 \mathrm{~h}$; después del filtrado y evaporado el solven- te, el extracto crudo metanólico fue recuperado con cloroformo ante la dificultad de su recuperación con $\mathrm{MeOH}$.

Análisis por cromatografía a gas.- El extracto crudo metanólico fue analizado en el Laboratorio de Química de la Universidad Estadual de Londrina, Paraná (Brasil), utilizando el sistema de cromatografía a gas (Budzianowsky 1995). El equipo utilizado fue un cromatógrafo a gas detector FID-SHIMADZU modelo GC. 17-D; columna HP-5, estableciéndose las siguientes condiciones de corrida: Inyector: $300{ }^{\circ} \mathrm{C}$, detector: $300{ }^{\circ} \mathrm{C}$, columna: $200{ }^{\circ} \mathrm{C} / 2 \mathrm{~min}$, temperatura final: $320{ }^{\circ} \mathrm{C}-10{ }^{\circ} \mathrm{C} /$ min, volumen de corrida: $2,7 \mathrm{~mL} / \mathrm{min}$, solvente: hexano, gas de arrastre: helio, tiempo de corrida: 30 min y patrones utilizados: plumbagina (5-hidroxi-2-metil-1,4-naftoquinona) y algunos compuestos hidrocarbonados de cadena larga.

Determinación de la actividad inhibitoria de la fracción clorofórmica del extracto crudo metanólico de $D$. capillaris.- Para la preparación de la suspensión Mycobacterium tuberculosis y diluciones con una espátula esterilizada se tomo el mayor número de colonias de las cepas y se colocaron en la pared interna de tubos de ensayo que contenían $5 \mathrm{~mL}$ de agua destilada esterilizada; se trituraron y mezclaron las colonias con una bagueta esmerilada esterilizada hasta obtener una suspensión homogénea; se dejó reposar durante 30 - 60 segundos hasta sedimentar y luego se tomó el sobrenadante y ajustó la turbidez de la suspensión (suspensión madre) comparando con el patrón de turbidez que contiene $1 \mathrm{mg} / \mathrm{mL}$ de masa bacilar. Se prepararon diluciones al décimo de $10^{-1}$ a $10^{-6}$ seleccionándose las diluciones $10^{-3}, 10^{-5}$ y $10^{-6}$.

Las soluciones de la fracción clorofórmica del extracto crudo metanólico de D. capillaris fueron preparadas tomando 312,5; 625 y $1250 \mathrm{mg}$ del extracto crudo metanólico y diluidos en 10 $\mathrm{mL}$ de cloroformo como volumen final; posteriormente, cada solución fue agregada a $250 \mathrm{~mL}$ del medio de cultivo Lowenstein-Jensen (L-J), obteniéndose las concentraciones de 1,25; 2,5 y $5 \mathrm{mg} / \mathrm{mL}$, respectivamente; luego se dispensó en tubos de ensayo tapa rosca a razón de $6 \mathrm{~mL}$ por tubo de ensayo; se llevó al coagulador a $85{ }^{\circ} \mathrm{C}$ por 45 minutos y finalmente a control de esterilización con las tapas ligeramente flojas a $37^{\circ} \mathrm{C} / 24 \mathrm{~h}$.

El proceso de siembra de $M$. tuberculosis se realizó en una cámara de seguridad biológica tipo II clase A, estableciéndose tres series de dilución: $10^{-3}, 10^{-5}$ y $10^{-6}$, eliminándose previamente el líquido condensado en el medio de cultivo. De cada una de las diluciones indicadas, se sembró $0,2 \mathrm{~mL}$ de la dilución en las siguientes réplicas: 2 tubos de ensayo con medio de cultivo L-J sin extracto crudo (control), 4 con medio de cultivo L-J con cloroformo (blanco), 5 con medio de cultivo L-J con extracto acuoso, 3 con medio de cultivo L-J con la fracción clorofórmica del extracto metanólico $1,25 \mathrm{mg} / \mathrm{mL}, 3$ con medio de cultivo L-J con la fracción clorofórmica del extracto metanólico $2,5 \mathrm{mg} /$ mLy 3 con medio de cultivo L-J con la fracción clorofórmica del extracto metanólico $5 \mathrm{mg} / \mathrm{mL}$. Estos tubos de ensayo fueron inicialmente mantenidos en posición horizontal, con rotación suave para distribuir homogéneamente la suspensión en la superficie del medio de cultivo; luego se llevaron a estufa a $37^{\circ} \mathrm{C}$.

Lectura e interpretación de resultados.- Las lecturas se realizaron a las 4 y 6 semanas de instalado el experimento. En el caso de los tubos de ensayo control la media de las colonias contadas indicó el número de bacilos sembrados. En el caso de 


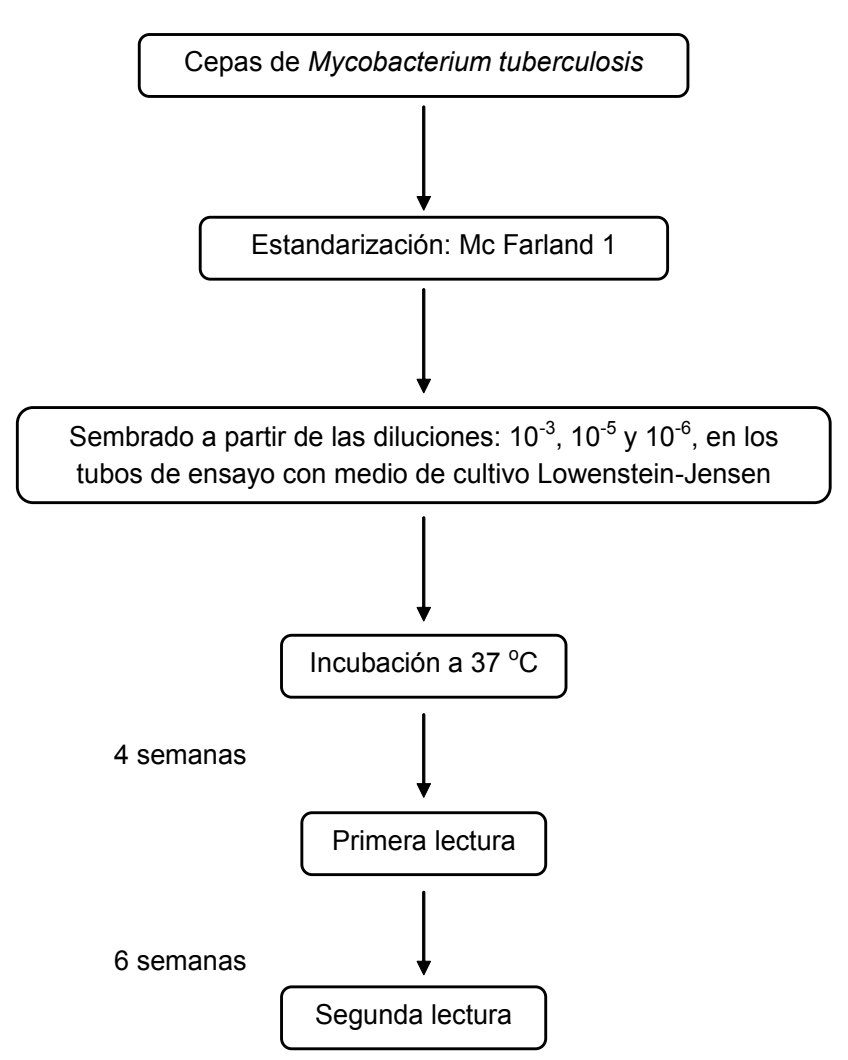

Figura 1. Flujograma en el proceso de siembra de Mycobacterium tuberculosis en medio de cultivo Lowenstein-Jensen suplementado con diferentes concentraciones de la fracción clorofórmica del extracto crudo metanólico de plantas in vitro de Drosera capillaris.

los tubos de ensayo con extracto crudo se parte del hecho de que la suspensión madre de la cepa en estudio contiene $1 \mathrm{mg} /$ $\mathrm{mL}$ de masa bacilar; sin embargo, la cantidad de bacilos en 1 mg de masa bacilar varía considerablemente de una cepa a otra, variación que puede ser de uno - cien millones de gérmenes/ $\mathrm{mL}$, por lo que fue necesario sembrar las diluciones $10^{-3}$ y $10^{-5}$. El procedimiento está resumido en la figura 1.

Tabla 1. Efecto inhibitorio in vitro de la fracción clorofórmica del extracto crudo metanólico de plantas in vitro de Drosera capillaris (tratamiento) sobre Mycobacterium tuberculosis (Promedio de colonias).

\begin{tabular}{|c|c|c|c|c|}
\hline \multirow{2}{*}{ Cepas $^{a}$} & \multirow{2}{*}{$\begin{array}{c}\text { Tratamiento } \\
(\mathrm{mg} / \mathrm{mL})\end{array}$} & \multirow{2}{*}{$\begin{array}{l}\text { Promedio } \\
\text { de colonias } \\
\left(\mathrm{N}^{\circ}\right)\end{array}$} & \multicolumn{2}{|c|}{ Porcentaje (\%) } \\
\hline & & & Inhibición & Resistencia \\
\hline \multirow{4}{*}{$\mathrm{C} 1$} & 0,0 & 240 & & \\
\hline & 1,25 & 79,7 & 66,8 & 33,2 \\
\hline & 2,5 & 56,0 & 76,7 & 23,3 \\
\hline & 5,0 & 56,0 & 76,7 & 23,3 \\
\hline \multirow{4}{*}{$\mathrm{C} 2$} & 0,0 & 252,5 & & \\
\hline & 1,25 & 101,0 & 60,0 & 40,0 \\
\hline & 2,5 & 30,0 & 88,1 & 11,9 \\
\hline & 5,0 & 17,3 & 93,1 & 6,9 \\
\hline \multirow{4}{*}{$\mathrm{C} 4$} & 0,0 & 325 & & \\
\hline & 1,25 & 195,0 & 40,0 & 60,0 \\
\hline & 2,5 & 35,5 & 89,1 & 10,9 \\
\hline & 5,0 & 52,7 & 83,8 & 16,2 \\
\hline
\end{tabular}

aLas cepas C3 y C5 fueron excluidas en la evaluación puesto que no desarrollaron el número mínimo de 200 colonias.



Figura 2. Perfil fitoquímico del extracto crudo metanólico de plantas de Drosera capillaris después de 12 meses de cultivo in vitro.

Determinación de la Concentración mínima inhibitoria

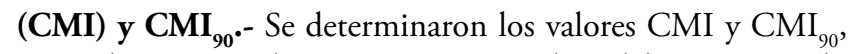
teniendo en cuenta la concentración más baja del extracto crudo capaz de inhibir el crecimiento visible de $M$. tuberculosis después del periodo de incubación y la concentración del extracto capaz de inhibir el 90\% del crecimiento bacteriano, respectivamente (Andrews 2001).

Diseño experimental y análisis estadístico.- Se utilizó el diseño de contrastación de hipótesis con estímulo creciente (Goode \& Hatt 1986) donde las cepas de M. tuberculosis fueron los grupos experimentales a las que se enfrentó diferentes concentraciones de la fracción clorofórmica del extracto crudo metanólico de D. capillaris. En el análisis estadístico de los datos se realizó el análisis de varianza así como las pruebas de comparaciones múltiples de Tukey con un nivel de significación de $0,05 \%$.

\section{Resultados}

La propagación clonal in vitro de $D$. capillaris se realizó utilizando como explantes hoja y planta íntegra. En el primer caso se formaron $5-10$ brotes por explante siguiendo el modelo de organogénesis directa, es decir, sin formación de callo, que luego de 6 meses de cultivo las plantas alcanzaron una altura promedio de $3 \mathrm{~cm}$, y en el segundo caso se formaron nuevas plantas a partir de las yemas axilares que alcanzaron una altura promedio de $4-5 \mathrm{~cm}$ en el lapso de 6 meses. En ambos casos las plantas formadas desarrollaron un óptimo sistema radicular, quedando habilitadas para su eventual transferencia a condiciones de invernadero.

El análisis cromatográfico mostró 8 picos claramente diferenciados, correspondiendo a diferentes sustancias, tal como lo indican sus particulares tiempos de retención. El pico de interés fue el 2, correspondiendo a la plumbagina, con un tiempo de retención de 3,76 min; los otros picos $(3-8)$ correspondieron a otras sustancias hidrocarbonadas de cadena larga de 18, 20, 24, 26, 27 y 32 carbones (Figura 2). 
Tabla 2. Prueba de significación de Tukey $(p<0,05)$ para tres cepas de Mycobacterium tuberculosis frente a diferentes concentraciones de la fracción clorofórmica del extracto crudo de plantas in vitro de Drosera capillaris.

\begin{tabular}{cccc}
\hline $\begin{array}{c}\text { Orden de } \\
\text { Mérito }\end{array}$ & $\begin{array}{c}\text { Concentración } \\
(\mathbf{m g} / \mathbf{m L})\end{array}$ & $\begin{array}{c}\text { Inhibición en } \\
\text { el crecimiento } \\
\mathbf{( \% )}\end{array}$ & $\begin{array}{c}\text { Significación } \\
(\mathbf{0}, \mathbf{0 5})\end{array}$ \\
\hline 1 & 1,25 & 55,6 & $\mathrm{a}$ \\
2 & 2,5 & 83,9 & $\mathrm{~b}$ \\
3 & 5,0 & 84,5 & $\mathrm{~b}$ \\
\hline
\end{tabular}

Los resultados del efecto de la fracción clorofórmica del extracto crudo metanólico de D. capillaris sobre $M$. tuberculosis se muestra en la Tabla 1, observándose que la inhibición en el crecimiento bacteriano fue modulada por el factor cepa y el factor concentración. Las cepas C3 y C5 fueron excluidas en la evaluación puesto que no desarrollaron el número mínimo de 200 colonias en el testigo, tal como lo recomienda la metodología utilizada (OPS, 1986), por tanto, únicamente fueron evaluadas las cepas C1, C2 y C4. En estas cepas, conforme se incrementaba la concentración del extracto $(1,25 ; 2,5$ y $5 \mathrm{mg} / \mathrm{mL})$ el porcentaje de inhibición también se incrementaba, desde $40 \%$ en la concentración $1,25 \mathrm{mg} / \mathrm{mL}$ para la cepa C4 hasta $93,1 \%$ en la concentración $5 \mathrm{mg} / \mathrm{mL}$ para la cepa C2. La prueba de Tukey, con 0,05 de significación indicó que las concentraciones 2,5 y $5 \mathrm{mg} / \mathrm{mL}$ fueron estadísticamente significativas y, asimismo, exhibieron la mayor capacidad de inhibición en el crecimiento de $M$. tuberculosis (Tabla 2).

La CIM para las cepas $\mathrm{C} 1$ y C2 fue $1,25 \mathrm{mg} / \mathrm{L}$ en tanto que la $\mathrm{CIM}_{90}$ para las cepas C2 y C4 fueron 5 y $2,5 \mathrm{mg} / \mathrm{L}$, respectivamente (Tabla 3).

\section{Discusión}

Una de las aplicaciones más importantes y prácticas del cultivo de tejidos vegetales es la micropropagación cuyos fundamentos fueron establecidos por Murashige (1974). En el caso de Drosera, varios autores han realizado trabajos en cultivo de tejidos utilizando como explantes semillas, hojas, ápices, raíces y flores, en medio de cultivo MS (Murashige \& Shoog 1962) y en varias combinaciones de las auxinas ácido indol-3-acético (AIA) y ANA con la citocinina benziladenina (BA), en bajas concentraciones (Šamaj et al. 1999); sin embargo, en nuestro trabajo, la auxina ANA $0,02 \mathrm{mg} / \mathrm{mL}$ no fue suplementada con citocinina alguna sino con $\mathrm{AG}_{3} 0,02 \mathrm{mg} / \mathrm{mL}$, alcanzando altos niveles de brotamiento y elongación de brotes y hojas. Adicionalmente, a la micropropagación, la utilización de otras técnicas del cultivo de tejidos, como la inducción de callos y el establecimiento de suspensiones celulares (Danelutte et al. 2005), abren la posibilidad de inducir la producción en gran escala de determinados metabolitos secundarios no solamente conocidos sino también

Tabla 3. Concentración Inhibitoria Mínima (CIM) y $\mathrm{CIM}_{90}$ de la fracción clorofórmica del extracto crudo metanólico de plantas in vitro de Drosera capillaris sobre Mycobacterium tuberculosis. ND, no determinado.

\begin{tabular}{ccc}
\hline Cepas & $\mathrm{CIM}(\mathbf{m g} / \mathbf{m L})$ & $\mathrm{CIM}_{\mathbf{9 0}}(\mathbf{m g} / \mathbf{m L})$ \\
\hline $\mathrm{C} 1$ & 1,25 & $\mathrm{ND}$ \\
$\mathrm{C} 2$ & 1,25 & 5,0 \\
$\mathrm{C} 4$ & $\mathrm{ND}$ & 2,5 \\
\hline
\end{tabular}

inéditos en condiciones naturales, sin necesidad de depredar la especie en su ambiente natural y más aún cuando se utilizan partes sensibles de la planta como en el caso raíces.

Numerosos estudios fitoquímicos han demostrado que varias especies de Drosera sintetizan dos grupos principales de metabolitos secundarios: naftoquinonas y flavonoides, tanto en plantas de campo como en plantas micropropagadas in vitro (Culham \& Gornall 1994, Zenk et al. 1969, Budzianowsky et al. 1993). Las naftoquinonas son compuestos que pertenecen a la familia química de los fenilpropanos de estructura C6 - C1 + C5. En Drosera destacan la plumbagina y la 7 -metiljuglona, biosintetizadas a partir de la tirosina en la ruta del acetato-polimanolato (Durand \& Zenk 1971, 1976); sin embargo, también han sido identificadas otras naftoquinonas consideradas menores como droserona, hidroxidroserona, droserona-5-glucósido, rosoloside e hidroxidroserona-5-glucósido y otras como biramentaceona y 2-metilnaftazarina-5-O-glucósido, consideradas artefactos producidos por extracción con solventes orgánicos (Šamaj et al. 1999). En nuestro trabajo, al igual que en plantas de campo de $D$. capillaris (Durand \& Zenk 1976) y de D. natalensis (Crouch et al. 1990), solamente fue posible la identificación de plumbagina pero no de 7-metiljuglona, en tanto que ambas sustancias fueron identificadas en D. capensis (Crouch et al. 1990, Wawrosch et al. 1996) y D. intermedia (Budzianowsky et al. 1993, Bonnet et al. 1984) y en el caso de D. hilaris (Wawrosch et al. 1996), D. rotundifolia (Wawrosch et al. 1996, Bonnet et al. 1984) y D. spathulata (Budzianowsky et al. 1993), únicamente se identificó 7-metiljuglona. Respecto a los flavonoides, si bien es cierto no se han reportado en nuestro trabajo, quercetina, hiperina, isoquercitrina, astragalina y miricetina-3-ramnosida (Budzianowsky et al. 1993) han sido identificados en $D$. spathulata y D. intermedia.

Mycobacterium tuberculosis es una bacteriana con la habilidad para adquirir resistencia a múltiples antibióticos lo que conlleva a la ocurrencia de cepas multidrogoresistente (MDR-TB) como resultado de un tratamiento inconsistente o parcial a lo que se suma la escasa colaboración del paciente; ello determina la necesaria utilización de drogas de segunda línea anti-TB, tales como aminoglicósidos, polipéptidos, fluoroquinolonas, etionamida y ácido $\rho$-aminosalicílico (Gibbons 2008). En efecto -y como es de deducir-, el tratamiento de la tuberculosis se basa en conceptos muy distintos a los de las demás infecciones bacterianas (Coll 2003). Mycobacterium tuberculosis tiene un tiempo de generación prolongada y la capacidad para entrar en periodos de latencia con una actividad metabólica limitada, lo cual dificulta la acción de los antimicrobianos. La bacteria presenta una resistencia natural a numerosos antibacterianos, por el hecho de poseer una pared compleja, muy hidrófoba, con una permeabilidad reducida para un gran número de compuestos (Jarlier \& Nikaido 1994). Al respecto, estudios genéticos han demostrado que la resistencia a los fármacos antituberculosos se debe a mutaciones cromosómicas espontáneas en los genes que codifican la diana del fármaco o enzimas implicadas en la activación del fármaco (Somoskovi et al. 2001). En tal sentido, se ha descrito la ocurrencia de enzimas modificantes como las betalactamasas (Kwon et al. 1995) o sistemas de eflujo (Cole et al. 1998), derivados de plantas, entre las que podemos contar a $D$. capillaris, que inhiben los mecanismos efluyentes de resistencia a los antibióticos bacterianos (Gibbons 2008).

Se considera que la acción del extracto crudo de D. capillaris 
sobre $M$. tuberculosis se realiza en la capa de lípidos de la pared celular, que es disuelta por la plumbagina, que ingresa al citoplasma por difusión a través del peptidoglicano; asimismo, la eventual presencia de flavonoides (Budzianowsky et al. 1993, Schölly \& Kapetanidis, 1989), contribuiría a degradar los lípidos de la pared celular bacteriana, propiciando la formación de poros y alterando la permeabilidad de la misma, lo que facilitaría la entrada de la plumbagina al citoplasma produciendo un ingreso desordenado de sustancias tóxicas y la salida de sustancias necesarias para la célula. Adicionalmente, una vez en el interior, la plumbagina seguiría actuando sobre las enzimas de la célula al reaccionar con los radicales $\mathrm{SH}$ y $\mathrm{NH}_{2}$, causando su completa inactivación y de esta manera obstaculizando su actividad enzimática (Walker 2000).

La utilización del extracto crudo de la planta tendría ciertas ventajas sobre la utilización de metabolitos secundarios puros puesto que se minimizaría el riesgo de inducir resistencia, además, que el uso de extractos heterogéneos de toda la biomasa de la planta podría inducir un efecto sinergístico sobre algún organismo específico (Leatemia \& Isman 2004). Al respecto, estudios realizados sobre la actividad biocida de extractos crudos comparando con sustancias puras (piperamidas), obtenidas de Piper tuberculatum, han demostrado un efecto más potente del extracto crudo sobre Aedes atropalpus (Scott et al. 2002) y Anticarsia gemmatalis (Navickiene et al. 2007), respectivamente, que cuando se utilizaron sustancias puras, aún en combinaciones binarias, terciarias y cuaternarias.

\section{Agradecimiento}

Al Br. Alexander Huamán Mera, por su asistencia técnica en la preparación del manuscrito.

\section{Literatura citada}

Andrews J.M. 2001. Determination of minimum inhibitory concentrations. J. Antimicrob. Chemother. 48 (Suppl. 1): 5-16.

Asencios L., N. Quispe, A. Mendoza-Ticona, E. Leo, L. Vásquez, O. Jave \& C. Bonilla. 2009. Vigilancia Nacional de la resistencia a medicamentos antituberculosos, Perú 20052006. Rev Peru Med Exp Salud Publica 26(3): 278-87.

Aziz M.A., A. Wright, A. Lazlo, A. De Muynck, F. Portaels, A. Van Deun, C. Wells, P. Nunn, L. Blanc \& M. 2006. Raviglione. Epidemiology of antituberculosis drug resistance (the Global Project on Anti-tuberculosis Drug Resistance Surveillance) an update analysis. The Lancet 368:2142-54.

Bonilla C. 2008. Situación de la tuberculosis en el Perú. Acta Med Per 25(3) 163-170

Bonnet M., M. Coumans, M. Holfinger, J.L. Ramaut \& T. Gaspar. 1984. High-performance gas chromatography of 1,4-naphtoquinones from Droseraceae. Chromatograph. 18: 621-622.

Brako L. \& J.L. Zarucchi. 1993. Catalogue of the Flowering Plants and Gymnosperms of Peru. Missouri Botanical Garden. St. Louis, Missouri.

Budzianowsky J. 1995. Naphtoquinones of Drosera spathulata from in vitro cultures. Phytochemistry 40: 1145-1148.

Budzianowsky J., L. Skrypczak, K. Kukulczanka. 1993. Phenolic compounds of Drosera intermedia and Drosera spathulata from in vitro cultures. Acta Hortic. 330: 277-280.

Cole S.T., R. Brosh, J. Parkhill, et al. 1998. Deciphering the biology of Mycobacterium tuberculosis from the complete genome sequence. Nature 393: 537-544.

Coll P. 2003. Fármacos con actividad frente a Mycobacterium tuberculosis. Enferm. Infecc. Microbiol. Clin. 21: 299-308.
Cronquist A. 1988. The Evolution and Classification of Flowering Plants. Second Edition USA. New York Botanical Garden. $555 \mathrm{pp}$.

Crouch I.J., J.F. Finnie \& J. van Staden. 1990. Studies on the isolation of plumbagin from in vitro and in vivo grown Drosera species. Plant Cell Tiss. Org. Cult. 21: 78-82.

Culham A. \& R.J. Gornall. 1994. The taxonomic significance of naphthoquinones in the Droseraceae. Biochem. System. Ecol. 22: 507-515.

Danelutte AP, Costantin MB, Delgado GE, Braz-Filho, R, Kato MJ. 2005. Divergence of secondary metabolism in cell suspension cultures and differentiated plants of Piper cernuum and P. crassinervium. J. Braz. Chem. Soc. 16(6B): 1425-1430.

Durand R. \& M.H. Zenk. 1971. Biosynthesis of plumbagin (5-hydroxy-2-methyl-1,4-naphtoquinone) via the acetate pathway in higher plants. Tetrahedron Lett. 32: 3009-3012.

Durand R. \& M.H. Zenk. 1976. The biosynthesis of the naphtoquinone 7-D methyljuglone. Biochem. Physiol. PLanz. 169: 213-217.

Finnie J.F. \& J. van Staden. 1993. Drosera spp. (Sundeaw): micropropagation and the in vitro production of plumbagin. In: Biotechnology in Agriculture and Forestry. Medicinal and Aromatic Plants XI. Y.P.S. Bajaj (ed.). Springer-Verlag, Berlin. 24: 164-167.

Gibbons S. 2008. Phytochemicals for bacterial resistance-strengths, weaknesses and opportunities. Planta Med. 74: 594-602.

Goode W.J. \& P.K. Hatt. 1986. Métodos de Investigación Social. Décima cuarta edic. Ed. Trilla, México. 236 p.

Jarlier V. \& H. Nikaido. 1994. Mycobacterial cell wall: Structure and role in natural resistance to antibiotics. FEMS Microbiol. Lett. 123: 11-18.

Jave O. 2009. Investigando en tuberculosis. ¿Dónde estamos, quiénos somos, hacia dónde nos dirigimos?. Rev Peru Med Exp Salud Publica 26(3): 276-77.

Kwon H.H., H. Tomioka \& H. Saito. 1995. Distribution and characterization of beta-lactamases of mycobacteria and related organisms. Tuber. Lung Dis. 76: 141-148.

Leatemia J. \& B. Isman. 2004. Toxicity and antifeedant activity of crude seed extract of Annona squamosa (Annonaceae) against lepidopteran pests and natural enemies. Int. J. Trop. Insect Sci. 24: 150-158.

Murashige T. \& F. Skoog. 1962. A revised medium for rapid growth and bioassays with tobacco tissue cultures. Physiol. Plant. 15: 473-479.

Murashige T. 1974. Plant propagation through tissue culture. Ann. Rev. Plant Physiol. 25: 135-166.

Navickiene H.M.D., J.E. Miranda, S.A. Bortoli, M.J. Kato, V. da S. Bolzani \& M. Furlan. 2007. Toxicity of extracts and isobutyl amides from Piper tuberculatum: potent compounds with potential for the control of the velvetbean caterpillar, Anticarsia gemmatalis. Pest Manag. Sci. 63: 399-403.

OPS (Organización Panamericana de la Salud). 1986. Manual de Normas y Procedimientos Técnicos para la Bacteriología de la Tuberculosis. Nota Técnica No 28. 42 p.

Šamaj J., M. Blehová, A. Repčák, A. Ovečka \& M. Bobák. 1999. Drosera species (sundew): In vitro culture and the production of plumbagine and other secondary metabolites. In: Biotechnology in Agriculture and Forestry. Medicinal and Aromatic Plants XI. Y.P.S. Bajaj (ed.). Springer-Verlag, Berlin. 43: 105-135.

Schölly T. \& Kapetanidis I. 1989. Flavonol and naphthoquinone glycosides of Drosera rotundifolia. Planta Med. 55: 611612.

Scott I.M., E. Puniani, T. Durst, et al. 2002. Insecticidal activity of Piper tuberculatum Jacq. Extracts: synergistic interaction of piperamides. Agr. Forest Entomol. 4: 137-144. 
Silva T.R. \& A.M. Giulietti. 1997. Levantamento das Droseraceae do Brasil. Bolet. Bot. Univ. São Paulo. 16: 75-105.

Simola I.K. 1978. The effect of several amino acids and some inorganic nitrogen sources on the growth of Drosera rotundifolia in long and short-day conditions. Z. Pflazenphysiol. 90: 61-68.

Somoskovi A., L.M. Parsons \& M. Salfinger. 2001. The molecular basis of resistance to isoniazide, rifampicin, and pyrazinamide in Mycobacterium tuberculosis. Respir. Res. 2: 164-168.

Ticona E. 2009. Tuberculosis: ¿Se agotó el enfoque biomédico?. Rev Peru Med Exp Salud Publica 26(3): 273-75.

Walker TS. 2000. Microbiología. Mc Graw-Hill Interamericana. México. 513 pp.
Wawrosch C., J. Markotai, B. Steinberger \& B. Kopp. 1996. In vitro - Vermehrung von Sonnentau- Arten. Sci. Pharm. 64: 621-622.

WHO (World Health Organization). 2006. WHO report global tuberculosis control surveillance, planning, financing. World Health Organization (WHO/HTM/TB/2006.362). Geneva. 246 pp.

Zenk M.H., M. Fubringer \& W. Steglich. 1969. Ocurrence and distribution of 7-metiljuglone and plumbagine in the Droseraceae. Phytochemistry 8: 2199-2200. 